\title{
A Novel Axial Modification and Simulation Analysis of Involute Spur Gear
}

\author{
Ningning Wang - Xueyi Li* - Kun Wang - Qingliang Zeng - Xiao Shen \\ Shandong University of Science and Technology College of Mechanical and Electronic Engineering, China
}

The transmission of spur gear mechanism may generate uneven load distribution because of machining error, assembly error, elastic deformation, and other factors, resulting in serious damage to the bearing capacity and service life of gears. To improve the contact condition of gear pairs and enhance the meshing performance and bearing capacity, this study proposed a novel axial modification method based on a composite modification curve with indefinite parameters and an evaluation method to evaluate modification effects. In addition to the surface equation of modified tooth was derived according to the composite modification curve, and the finite element model was built for gear pair. After conducting simulation analysis for the meshing process, the location and the shape of contact area as well as the other results can be acquired. In addition, the modification parameters can be optimized by performing orthogonal experiments for modified gear pairs; thus, the ideal modification effect is obtained at a specific operating condition. Moreover, comparison analysis was performed, and the results show that the phenomenon of uneven load distribution is dramatically improved when the gear pair was modified with optimized parameters, and the bearing capacity of the gear pair was increased. Finally, using the optimized parameters to trial-produce gears and conducting running-in tests, the effectiveness and the practicability of the method proposed in this study were verified.

Keywords: uneven load distribution, axial modification, simulated analysis, contact area, stress

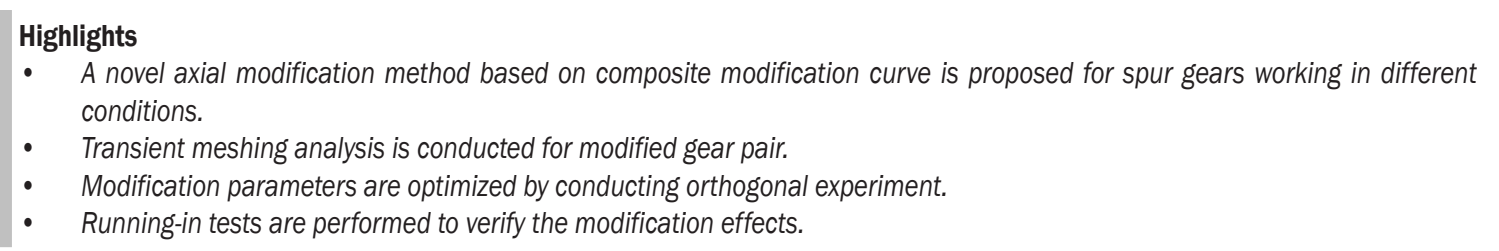

\section{INTRODUCTION}

As key components to bear load and transmit power, gear units are widely used in mechanisms, and the bearing capacity and service life significantly influence the performance of the equipment. However, the gear teeth and the shaft may generate deformation during the transmission, and there are machining errors and assembly errors. These factors may lead to the uneven load distribution along the tooth width direction, and may decrease the bearing capacity and service life, even resulting in the gear failure or production accidents. Axial modification, which can correct the shape and position of contact area by changing the structure of gear, is the most effective solution to solve the above issues. While Korotkin and Gazzaev [1] researched the gear transmission system with axial deviation, and they found that using the traditional method to calculate bearing capacity overestimated it in the gear units. Moreover, the shape of tooth surface changes with axial modification, which is different from the standard involute tooth surface. Thus, it is much more difficult to estimate the bearing capacity of gear systems with modification, and the design process is more complex. Therefore, investigating the modification theory and calculating the strength as well as evaluating the performance of modified gears must be performed.

Since the theory of modification was proposed, numerous researchers have conducted studies on the problem from different aspects to improve the meshing performance of gear transmission. For example, Barbieri et al. [2] and [3] and Bonori et al. [4] explored the effects of profile modification using tooth contact analysis (TCA); furthermore, they used a genetic algorithm to optimize the method. An original method to calculate the transmission efficiency was proposed by Baglioni et al. [5], and the influence of tip relief was also discussed. Liu and Parker [6], Chenet al. [7], Wu et al. [8], Subramanian and Srinivasan [9] and Farshad et al. [10] all investigated the profile modification to reduce the vibration in gear transmissions. Moreover, in order to decrease the Hertzian stresses [11] and reduce the damage of thermal deformation [12], some researchers applied tooth width modification for gear pairs. Although these modification methods can improve the transmission performance for gear units, the uneven load distribution was not concerned in these studies.

Nejad et al. [13] conducted axial modification for the sun wheel in a planetary gear transmission system, and the analysis results indicated the effects 
of axial modification. Furthermore, loaded tooth contact analysis (LTCA) was performed by Li [14] and [15] to research the influence of machining error and axial modification on surface contact stress and root bending stresses. Some researchers like Hotait and Kahraman [16] discussed the effect of shaft deviation and modification on the load distribution and stresses, and it was found that large deviations may increase the root bending stress and contact stress. Based on the gear geometry, Hsu and Su [17] and Kawalec and Wiktor [18] derived the cutter equations to machinemodified gears. All of these studies illustrate the importance of axial modification to improve the gear meshing, however, modification parameters were not optimized. Thus, Alessio et al. [19] viewed decreasing the contact stress and the fluctuation of transmission error as objective, and the modified gear was optimized by performing a load distribution program (LDP). However, it was not verified by conducting experiments in practice. In the aspects of modelling and simulation analysis, some people conducted static analysis for gear pair instead of transient meshing analysis, and the transient meshing performance cannot be obtained at all. Moreover, researchers, including Tesfahunegn et al. [20], established the model in Pro/E, while analysed in other simulation software. It may lead to the data loss, and the analysis may be failed.

To overcome the defects in the previous studies, a new method to obtain an ideal modification for gear pair was proposed in this study based on the composite modification curve to eliminate the uneven load distribution. Taking a pair of gears as an example, the implementation process of this method was introduced in detail. Specifically, the model of modified gear pair was precisely established based on cubic B-spline interpolation, and the modification parameters were optimized based on orthogonal experiments. Finally, according to the optimized parameters, the gear pair was trail-produced, and the method proposed in this study was verified by a performing running-in test.

The rest of this paper is organized as follows. Section 1 mainly introduces the theory of axial modification. Section 2 shows the method to analyse the meshing performance of a modified gear pair, including parametric modelling and analysing the meshing characteristic. The method of optimizing modification parameters based on an orthogonal experiment is briefly introduced in Section 3. Taking a pair of gears as an example in Section 4, the final design results were obtained based on the method proposed, and a series of comparative tests are conducted in this section. Section 5 indicates the process and results of running-in test. At last, the conclusions are summarized in Section 6.

\section{AXIAL MODIFICATION METHOD OF INVOLUTE SPUR GEAR}

There is deviation along the tooth width direction because of machining error, assembly error, and elastic deformation. This may lead to uneven load distribution and the gear teeth may be broken, which is very harmful to the transmission. Hence, axial modification should be applied to the spur gear pair, also known as lead crowning modification. Thus, the contact area moves to the centre of the tooth width and the above issues are solved. Ordinarily the modification is only conducted to the smaller gear in order to decrease the machining cost.

The shape of single tooth with axial modification looks like the solid part in Fig. 1a, while the gear tooth without modification looks like the dotted portion in the figure. A pair of gear teeth meshing with each other is as shown in Fig. 1b, where $c_{c}$ is the maximum amount, $b$ is the width of the gear, $b_{c}$ represents the distance from the centre of modification to the tooth end, $C_{m}$ is the modification curve, $b_{c i}$ and $c_{c i}$ respectively represents the distance between the centre of modification to any point $P_{i}$ and the modification amount at that point, $F_{\beta \gamma}$ is the value of axial deviation, and $\gamma_{d}$ is the angle of deviation. It can be found that the shape of modified gear tooth depends on the distance $b_{c}$, the modification amount $c_{c}$ and the modification curve $C_{m}$.

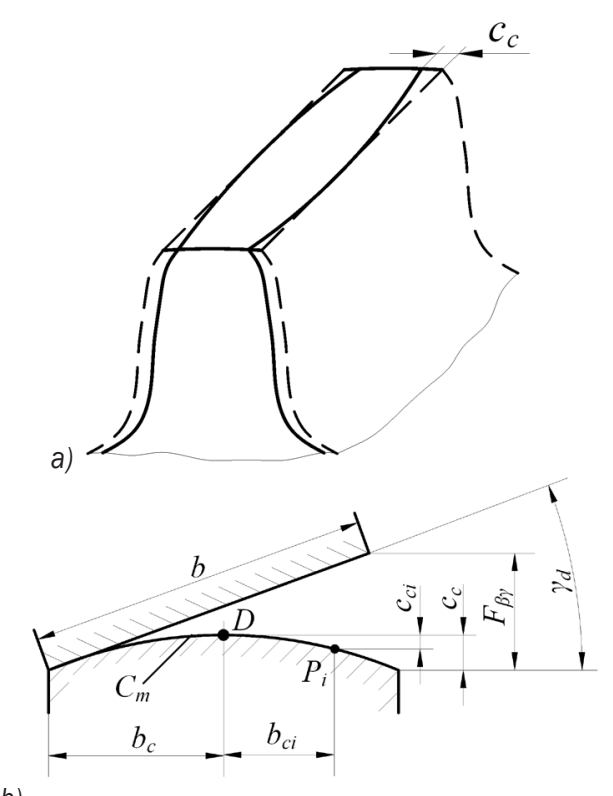

b)

Fig. 1. Axial modification for gear; a) single gear tooth; and b) a pair of gear teeth 
Most of current literature indicates that the modification centre coincides with the tooth width centre. However, it is not the best choice in practice. The position of the modification centre should be adjusted with working condition of gear transmission, which has been discussed in reference [21], and a reasonable equation to calculate the position of modification centre is presented as Eq. (1) according to the reference.

$$
b_{c}=\sqrt{\frac{8 F_{m} b}{C_{\gamma} F_{\beta \gamma}}} .
$$

In Eq. (1), $F_{m}$ is peripheral force, and $C_{\gamma}$ is meshing stiffness.

In addition, the maximum modification amount and the axial deviation can also be calculated, too. The detailed calculating methods are not presented here due to the limitations of space. The position of modification centre is shown in Fig. 2, $b_{c}$ and $R_{c}$ respectively represents the distance between the modification centre to the tooth end and the radius of modification when the modification centre coincides with the centre of tooth width, and $b_{c}{ }^{\prime}$ as well as $R_{c}{ }^{\prime}$ respectively represent the distance and the radius when the two centres do not coincide with each other.

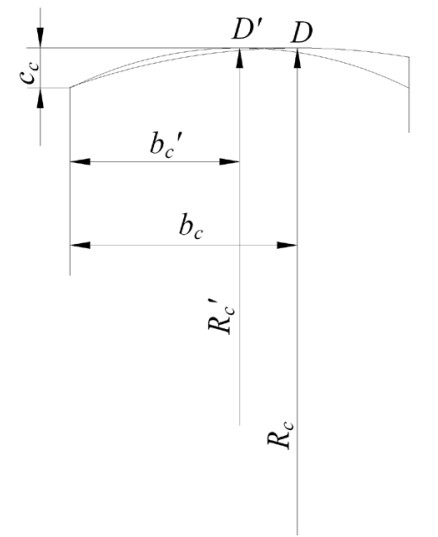

Fig. 2. Diagram of the modification centre

The modification curve has an important influence on the meshing performance of the gear. The circular curve is the most commonly used because it is easy to process; however the contact area of the gear pair may be a little small, and may decrease the bearing capacity. A composite power curve is proposed in this study, and the modification amount of any point $P_{i}$ on the curve is as follows:

$$
c_{c i}=\varepsilon c_{c} \cdot\left(\frac{b_{c i}}{b_{c}}\right)^{\lambda}+(1-\varepsilon) c_{c} \cdot\left(\frac{b_{c i}}{b_{c}}\right)^{\phi} .
$$

In Eq. (2), $b_{c i}$ represents the distance from the point $P_{i}$ to the modification centre, $\mathrm{mm} ; \varepsilon$ is the superposition coefficient, $0<\varepsilon<1 ; \lambda$ and $\varphi$ are power of polynomial, $1 \leq \lambda \leq 3,1 \leq \varphi \leq 3$. Any shape of modification curve can be obtained by adjusting $\varepsilon$, $\lambda$ as well as $\varphi$. As for gear pairs working in different conditions, modification parameters should be different too, and the universal circular curve could not satisfy all the gear pairs. Thus, ideal modification ways can be obtained for different gear pairs based on the composite power curve.

\section{MESHING PERFORMANCE ANALYSIS FOR MODIFIED GEAR PAIR}

In order to assess the meshing performance and modification effects, the modified gear pair needs to be trail-produced abnormally, followed by observing the position of contact area, the shape of contact area, tooth deformation after conducting running-in tests. This kind of process is complex and wasteful. Therefore, finite element analysis is performed for modified gear pairs in this study, and the stresses as well as meshing performance can be read after simulation on computers.

\subsection{Parametric Modelling for Modified Gear Pair}

According to the bottom-up modelling ideas, the finite element model for modified gear pairs can be established using ANSYS parametric design language (APDL). Because the tooth surface with modification is a complex surface rather than straight surface along the axial direction, it is difficult to build the model precisely. In this study, the point matrix of the modified tooth surface can be established layer by layer along the modification curve, and then the method of cubic B-spline interpolation is used to build the tooth surface.

If the gear is conducted with axial modification, the coordinates of point $P_{i}$ at any $k$-section are shown as Eq. (3):

$$
\left\{\begin{array}{l}
r_{k i}=\frac{r_{b}}{\cos \alpha_{k i}} \\
\theta_{k i}=\left(\tan \alpha_{k i}-\alpha_{k i}+\frac{c_{c i}}{r_{a}}\right) \cdot \frac{180}{\pi}, \\
b_{k i}=b_{c i}
\end{array}\right.
$$


where $r_{b}$ and $r_{a}$ respectively represents the radius of the basic circle and addendum circle, and $\alpha_{k i}$ is the pressure angle of point $P_{i}$, which is as follows:

$$
\alpha_{k i}=\frac{\alpha_{a}-(i-1) \cdot\left(\alpha_{a}-\alpha_{f}\right)}{n-1} \cdot \frac{\pi}{180} .
$$

In the equation, $n$ is the number of selected points on the profile curve, $\alpha_{a}$ and $\alpha_{f}$ respectively represent the pressure angle of tooth addendum and tooth root.

Calculating the coordinates of points on the tooth surface along the axial direction using the above equations, the point matrix can be established based on the coordinates. Then the modified tooth surface can be built by performing the method of cubic B-spline interpolation mentioned in literature [22]. Besides, the model of bigger gear without modification is built using universal method. According to the previous work [23] our research group done, the simplified meshing model of gear pair can also be built. Specially, in order to imitate the axial deviation between the gear pair, the driven gear should rotate based on the value of deviation, and the rotation angle is shown as Eq. (5):

$$
\omega=\arctan \left(\frac{F_{\beta \gamma}}{B_{2}}\right) \cdot \frac{180}{\pi},
$$

where $B_{2}$ represents the tooth width of the driven gear.

Before the transient meshing analysis is performed for a modified gear pair, face-to-face contact should be conducted between the gear pair, and then build a rigid bond between the centre node and the inner surface for each gear in order to apply loads and constraint easily. Moreover, the rotate speed and torque should be applied respectively to the centre nodes. Thus, the finite element model of modified gear pair can be solved. The finite element model of modified gear pair looks like Fig. 3, and the detail process of modelling is shown in Fig. 4.

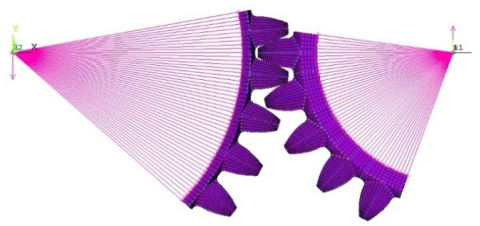

Fig. 3. Finite element model of modified gear pair

\subsection{Meshing Performance Analysis of Modified Gear Pair}

After conducting transient meshing analysis, many analysis results can be obtained. The variation of root bending stress and surface contact stress during the transmission can be drawn as a line chart (Fig. 5), and the change law of stresses can be obtained from the chart. It can be found that the meshing state of the gear pair has experienced the transformation from single tooth meshing to double tooth meshing and then to single tooth meshing. Thus, the stresses are changed with the variation of meshing state.

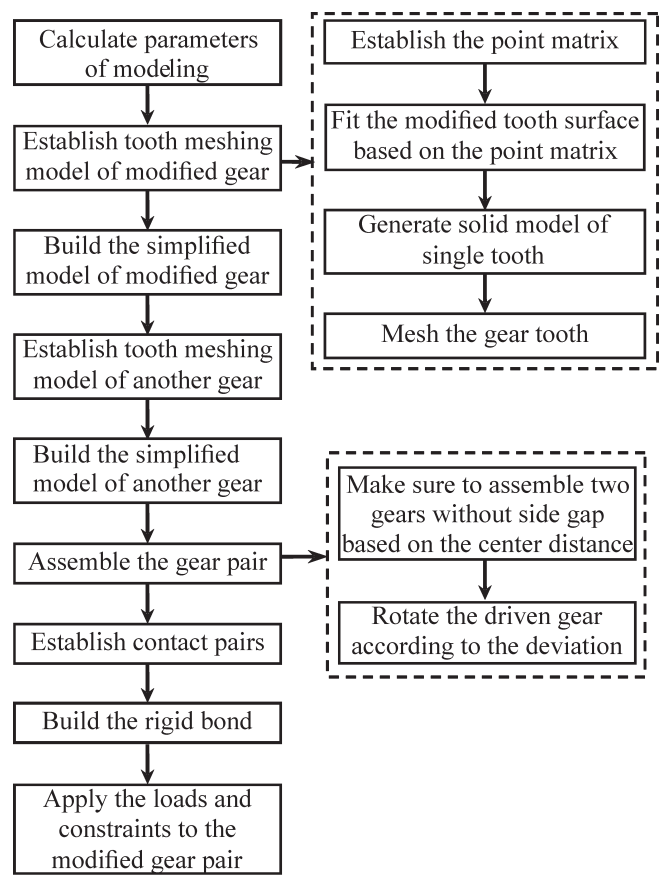

Fig. 4. Flow chart of modelling

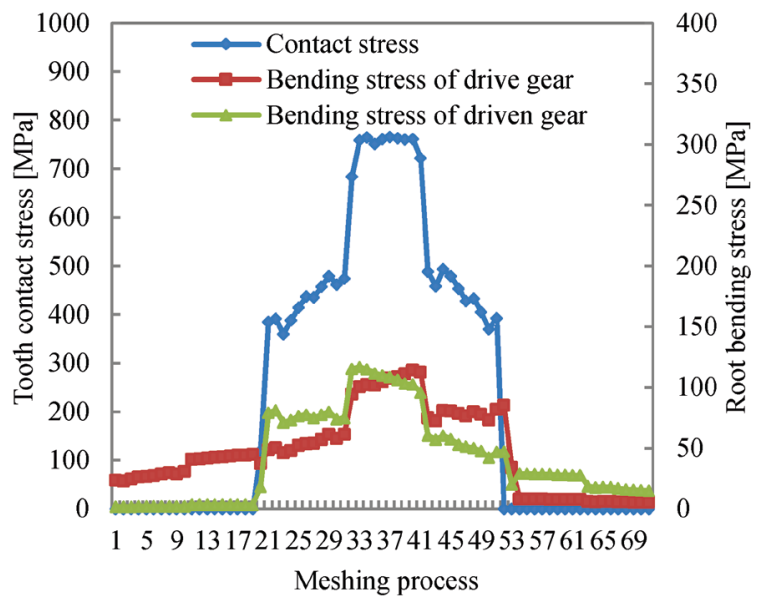

Fig. 5. Variation of stresses

Besides, the maximum of every stress and corresponding meshing position can be separately read from the line chart. Acquiring the meshing positions of maximum root-bending stresses of the drive gear and the driven gear, the static analyses are conducted respectively at these two positions. Thus, tooth deformation can be read after analysis, and the 
bigger one is the maximum deformation during the transmission.

Moreover, the maximum of contact stress and corresponding worst meshing position can be found from the line chart. The distribution of contact stress can be obtained at the worst meshing position in detail. Moreover, the contour map of the contact stress can be read in this meshing position too. The shape and location of contact area can be observed from the contour map. Usually, the contour map of contact stress looks like Fig. 6. When comparing the location and the shape of contact area as well as the distribution of contact stress when the gear pair is without modification or with other modification method, the modification effects can be acquired.

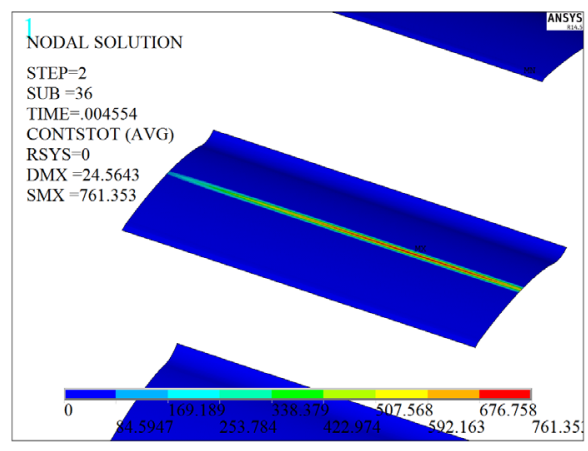

Fig. 6. Contour map of the contact stress

The above is a part of results can be read after conducting transient meshing analysis. These results reflect the meshing performance of modified gear pair; moreover, they also lay the foundation for the following orthogonal experiment as well as comparative analysis.

\section{OPTIMIZATION OF MODIFICATION PARAMETERS BASED ON ORTHOGONAL EXPERIMENT}

As mentioned above, modification parameters should be different for gear pairs working in different conditions. To obtain the ideal modification effect, modification parameters are optimized by conducting orthogonal experiment in this study based on the evaluation method for modified gear pair mentioned in the third section. As a kind of method to solve multi-level and multi-factor issues, the orthogonal method is easy to implement and can greatly decrease the number of tests. Thus, numerous researchers, such as Perec [24], arranged their experiments by using orthogonal tables. It can be found that there are three factors in this study, superposition coefficient $\varepsilon$, power $\lambda$ as well as $\varphi$, and every factor can be divided into many levels. If the division level is too much, the experiment efficiency will be reduced. Or if it is too small, the experiment effect couldn't be very well. These three factors are divided into five levels in this study, and the details are shown in Table 1.

Table 1. Factors and levels of orthogonal experiment

\begin{tabular}{cccc}
\hline \multirow{2}{*}{ Levels } & \multicolumn{3}{c}{ Factors } \\
\cline { 2 - 4 } & Coefficient $\varepsilon$ & Power $\lambda$ & Power $\varphi$ \\
\hline 1 & 0.1 & 1 & 1 \\
\hline 2 & 0.3 & 1.5 & 1.5 \\
\hline 3 & 0.5 & 2 & 2 \\
\hline 4 & 0.7 & 2.5 & 2.5 \\
\hline 5 & 0.9 & 3 & 3 \\
\hline
\end{tabular}

A suitable orthogonal table for this experiment can be chosen according to the number of factors and levels. Because there are three factors, and every factor is divided into five levels, orthogonal array $\mathrm{L}_{25}$ $\left(5^{6}\right)$ was used in this study, and the three columns at the back of the table were ignored. Twenty-five tests were conducted in total, and the details of each test are shown in Table 2.

Table 2. Scheme of orthogonal experiment

\begin{tabular}{|c|c|c|c|}
\hline \multirow{2}{*}{$\begin{array}{c}\text { Test } \\
\text { number }\end{array}$} & \multicolumn{3}{|c|}{ Factors } \\
\hline & Coefficient $\varepsilon$ & Power $\lambda$ & Power $\varphi$ \\
\hline 1 & 0.1 & 1 & 1 \\
\hline 2 & 0.1 & 1.5 & 1.5 \\
\hline 3 & 0.1 & 2 & 2 \\
\hline 4 & 0.1 & 2.5 & 2.5 \\
\hline 5 & 0.1 & 3 & 3 \\
\hline 6 & 0.3 & 1 & 1.5 \\
\hline 7 & 0.3 & 1.5 & 2 \\
\hline 8 & 0.3 & 2 & 2.5 \\
\hline 9 & 0.3 & 2.5 & 3 \\
\hline 10 & 0.3 & 3 & 1 \\
\hline 11 & 0.5 & 1 & 2 \\
\hline 12 & 0.5 & 1.5 & 2.5 \\
\hline 13 & 0.5 & 2 & 3 \\
\hline 14 & 0.5 & 2.5 & 1 \\
\hline 15 & 0.5 & 3 & 1.5 \\
\hline 16 & 0.7 & 1 & 2.5 \\
\hline 17 & 0.7 & 1.5 & 3 \\
\hline 18 & 0.7 & 2 & 1 \\
\hline 19 & 0.7 & 2.5 & 1.5 \\
\hline 20 & 0.7 & 3 & 2 \\
\hline 21 & 0.9 & 1 & 3 \\
\hline 22 & 0.9 & 1.5 & 1 \\
\hline 23 & 0.9 & 2 & 1.5 \\
\hline 24 & 0.9 & 2.5 & 2 \\
\hline 25 & 0.9 & 3 & 2.5 \\
\hline
\end{tabular}


Transient meshing analyses were performed for a gear pair, which is modified using parameters according to Table 2. By observing the position and the shape of contact area as well as by comparing the stresses and tooth deformation in every test, modification parameters can be optimized and the ideal modification way for the gear pair is obtained.

\section{SIMULATION AND COMPARATIVE ANALYSIS}

Numerous spur gear pairs were performed to find suitable modification ways based on the method proposed in this study, and all results verified the validity of the method. A pair of gears used in an automobile transmission system is introduced as an example, and axial modification design is conducted on the gear pair. Furthermore, the meshing performance and modification effect are evaluated. The specific parameters of the gear pair are shown in Table 3.

Table 3. Parameters of the gear pair

\begin{tabular}{llc}
\hline \multirow{2}{*}{ Number of teeth } & Drive gear & 23 \\
\cline { 2 - 3 } & Driven gear & 34 \\
\hline \multirow{2}{*}{$\begin{array}{l}\text { Modification } \\
\text { Coefficient }\end{array}$} & Drive gear $x_{1}$ & 0.2322 \\
\cline { 2 - 3 } & Driven gear $x_{2}$ & 0.0259 \\
\hline \multirow{2}{*}{ Tooth width $[\mathrm{mm}]$} & Drive gear $B_{1}$ & 20 \\
\cline { 2 - 3 } & Driven gear $B_{2}$ & 20 \\
\hline Module $m$ & 4 \\
\hline Pressure angle $\alpha\left[^{\circ}\right]$ & 20 \\
\hline The rotate speed of drive gear [r/min] & 1080 \\
\hline The torque of drive gear $[\mathrm{Nm}]$ & 110 \\
\hline Load factor & 1.557 \\
\hline Axial deviation $[\mu \mathrm{m}]$ & 18.72 \\
\hline
\end{tabular}

For this pair of gears, the allowable maximum contact stress is $\left[\sigma_{\mathrm{H}}\right]=945 \mathrm{MPa}$, the allowable root bending stress of the drive gear is $\left[\sigma_{\mathrm{F}}\right]_{1}=376.43 \mathrm{MPa}$, and the allowable root bending stress of driven gear is $\left[\sigma_{\mathrm{F}}\right]_{2}=377.14 \mathrm{MPa}$. Using the traditional method to calculate stresses of the gear pair, the contact stress is $844.05 \mathrm{MPa}$, the root bending stress of the drive gear is $136.24 \mathrm{MPa}$, and the root bending stress of the driven gear is $137.59 \mathrm{MPa}$. All stresses are less than the allowable stress respectively, which can meet strength requirement. However, the traditional design method mainly depends on the experience of researchers, and the design results need to be revised based on some correction factors. Sometimes, it could not precisely estimate the working condition, tooth deformation and so on. Thus, the design results might be unreasonable and could not be applied in practice.
Therefore, the transient meshing analysis was conducted on the gear pair without modification shown in Table 3, and axial deviation was considered in the modelling process to simulate the actual situation. Analysis results were read after simulation. It can be found that the contact stress of the gear pair is $1275.3 \mathrm{MPa}$, the root bending stress of the drive gear is $157.27 \mathrm{MPa}$, and the root bending stress of the driven gear is $163.17 \mathrm{MPa}$. Furthermore, the contour map of contact stress on the tooth surface is shown in Fig. 7. The figure indicates that there is severe uneven load distribution, and the contact stress exceeds the allowable value, which means the gear pair cannot meet the strength requirement. Hence, it is very important to conduct axial modification for the gear pair.

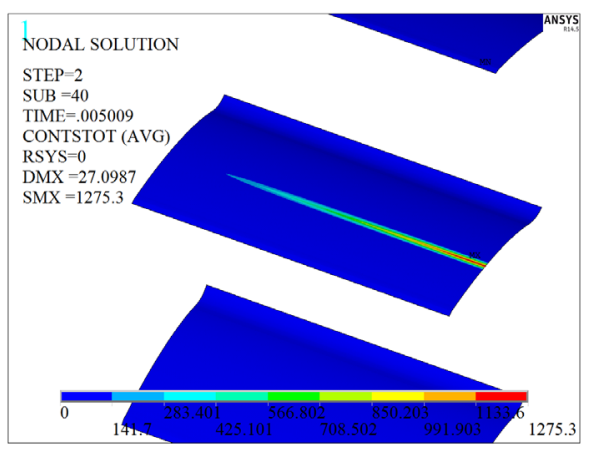

Fig. 7. Contour map of the contact stress

In order to obtain ideal modification parameters, an optimization experiment was conducted on the gear pair based on the orthogonal method, as mentioned above. The experiment's results are shown in Table 4.

Comparing the position and shape of contact area, stresses of modified gear pair as well as tooth deformation after completing all the orthogonal experiment, the modification parameters can be optimized, and the most suitable modification method is obtained. It can be found that there are six tests, test $3,7,12,17,19$, and 23 , the distances from the centre of contact area to the centre of tooth width are short in these tests, and the shape of contact area is narrow and long. Furthermore, the stress values indicate that the gear pair satisfies strength requirement in these tests, thus the parameters used in the test with the smallest tooth deformation are optimized parameters for the gear pair. Particularly, tooth deformation in Test 7 is the smallest. Therefore, the parameters in Test 7 are optimized, and the formula of the modification curve is as shown in Eq. (6):

$$
c_{c i}=0.3 c_{c} \cdot\left(\frac{b_{c i}}{b_{c}}\right)^{1.5}+0.7 c_{c} \cdot\left(\frac{b_{c i}}{b_{c}}\right)^{2} .
$$


Table 4. Experiment results

\begin{tabular}{|c|c|c|c|c|c|c|c|c|}
\hline \multirow[b]{2}{*}{ Test number } & \multicolumn{3}{|c|}{ Factors } & \multicolumn{5}{|c|}{ Experiment results } \\
\hline & $\begin{array}{c}\text { Coefficient } \\
\varepsilon\end{array}$ & $\begin{array}{c}\text { Power } \\
\lambda\end{array}$ & $\begin{array}{c}\text { Power } \\
\varphi\end{array}$ & $\begin{array}{c}\text { Contact } \\
\text { stress [MPa] }\end{array}$ & $\begin{array}{l}\text { Root bending } \\
\text { stress of drive } \\
\text { gear [MPa] }\end{array}$ & $\begin{array}{l}\text { Root bending } \\
\text { stress of driven } \\
\text { gear [MPa] }\end{array}$ & $\begin{array}{c}\text { Tooth } \\
\text { deformation } \\
\times 10^{-3}[\mathrm{~mm}] \\
\end{array}$ & $\begin{array}{l}\text { Distance between } \\
\text { contact pot to centre } \\
\text { of tooth width [mm] }\end{array}$ \\
\hline 1 & $\varepsilon 1$ & $\lambda 1$ & $\varphi 1$ & 826.74 & 118.33 & 120.81 & 14.806 & 9 \\
\hline 2 & $\varepsilon 1$ & $\lambda 2$ & $\varphi 2$ & 749.48 & 114.83 & 117.20 & 13.392 & 7 \\
\hline 3 & $\varepsilon 1$ & $\lambda 3$ & $\varphi 3$ & 779.20 & 114.11 & 116.0 & 13.468 & 4 \\
\hline 4 & $\varepsilon 1$ & $\lambda 4$ & $\varphi 4$ & 829.02 & 114.93 & 117.83 & 13.941 & 3 \\
\hline 5 & $\varepsilon 1$ & $\lambda 5$ & $\varphi 5$ & 875.54 & 116.23 & 119.29 & 14.412 & 4 \\
\hline 6 & $\varepsilon 2$ & $\lambda 1$ & $\varphi 2$ & 771.18 & 115.87 & 118.28 & 13.811 & 8 \\
\hline 7 & $\varepsilon 2$ & $\lambda 2$ & $\varphi 3$ & 761.27 & 114.33 & 116.88 & 13.371 & 4 \\
\hline 8 & $\varepsilon 2$ & $\lambda 3$ & $\varphi 4$ & 813.63 & 114.68 & 117.53 & 13.798 & 3 \\
\hline 9 & $\varepsilon 2$ & $\lambda 4$ & $\varphi 5$ & 861.32 & 115.84 & 118.85 & 14.271 & 4 \\
\hline 10 & $\varepsilon 2$ & $\lambda 5$ & $\varphi 1$ & 786.84 & 117.54 & 120.10 & 13.832 & 7 \\
\hline 11 & $\varepsilon 3$ & $\lambda 1$ & $\varphi 3$ & 766.64 & 116.20 & 118.67 & 13.602 & 7 \\
\hline 12 & $\varepsilon 3$ & $\lambda 2$ & $\varphi 4$ & 781.80 & 117.40 & 114.74 & 13.442 & 4 \\
\hline 13 & $\varepsilon 3$ & $\lambda 3$ & $\varphi 5$ & 827.39 & 115.16 & 118.07 & 13.937 & 4 \\
\hline 14 & $\varepsilon 3$ & $\lambda 4$ & $\varphi 1$ & 778.70 & 116.46 & 119.01 & 13.613 & 6 \\
\hline 15 & $\varepsilon 3$ & $\lambda 5$ & $\varphi 2$ & 805.52 & 115.30 & 118.14 & 13.747 & 4 \\
\hline 16 & $\varepsilon 4$ & $\lambda 1$ & $\varphi 4$ & 784.26 & 117.20 & 119.72 & 13.911 & 8 \\
\hline 17 & $\varepsilon 4$ & $\lambda 2$ & $\varphi 5$ & 776.45 & 115.82 & 118.37 & 13.512 & 5 \\
\hline 18 & $\varepsilon 4$ & $\lambda 3$ & $\varphi 1$ & 763.31 & 115.36 & 117.82 & 13.431 & 6 \\
\hline 19 & $\varepsilon 4$ & $\lambda 4$ & $\varphi 2$ & 800.33 & 114.75 & 117.58 & 13.675 & 4 \\
\hline 20 & $\varepsilon 4$ & $\lambda 5$ & $\varphi 3$ & 846.65 & 115.58 & 118.56 & 14.127 & 4 \\
\hline 21 & $\varepsilon 5$ & $\lambda 1$ & $\varphi 5$ & 810.52 & 118.07 & 120.57 & 14.461 & 8 \\
\hline 22 & $\varepsilon 5$ & $\lambda 2$ & $\varphi 1$ & 756.03 & 115.18 & 117.56 & 13.527 & 8 \\
\hline 23 & $\varepsilon 5$ & $\lambda 3$ & $\varphi 2$ & 774.83 & 114.18 & 116.85 & 13.433 & 4 \\
\hline 24 & $\varepsilon 5$ & $\lambda 4$ & $\varphi 3$ & 823.89 & 114.85 & 117.73 & 13.894 & 3 \\
\hline 25 & $\varepsilon 5$ & $\lambda 5$ & $\varphi 4$ & 870.81 & 116.10 & 119.15 & 14.365 & 4 \\
\hline
\end{tabular}
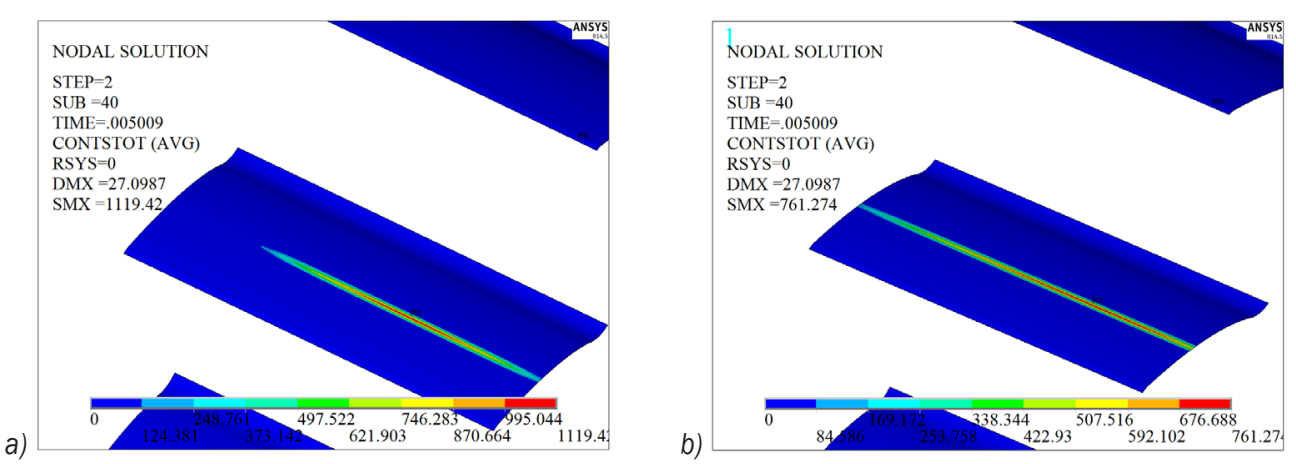

Fig. 8. Contour map of contact stress; a) universal modification method; and b) the optimized method

Moreover, transient meshing analysis was conducted for the gear pair with arc modification curve in order to expose the effects of different modification methods. The details of comparison are as follows.

If the gear pair is modified using universal modification method, the contour map of contact area is shown as Fig. 8a. Comparing Fig. 8a with Fig. 7, the phenomenon of uneven load distribution is improved when the gear pair is modified, and the contact area closes to the centre of gear. However, the contact area is not long enough, and the contact stress is still higher than the allowable value. The universal modification method is not suitable for the gear pair 
shown in Table 3. When the gear pair is modified using the method proposed in this study, the contour map of contact stress is shown as Fig. 8b. It can be found from the figure that uneven load distribution is dramatically improved, and the contact stress is lower than the allowable value. The gear pair satisfies the strength requirement.

In addition, the line chart of contact stress value along the tooth width is made, as in Fig. 9, in order to observe the effect of different modification methods on the distribution of contact stress more intuitively. The chart indicates that the distribution is more uniform when the gear pair is modified with the optimized parameters.

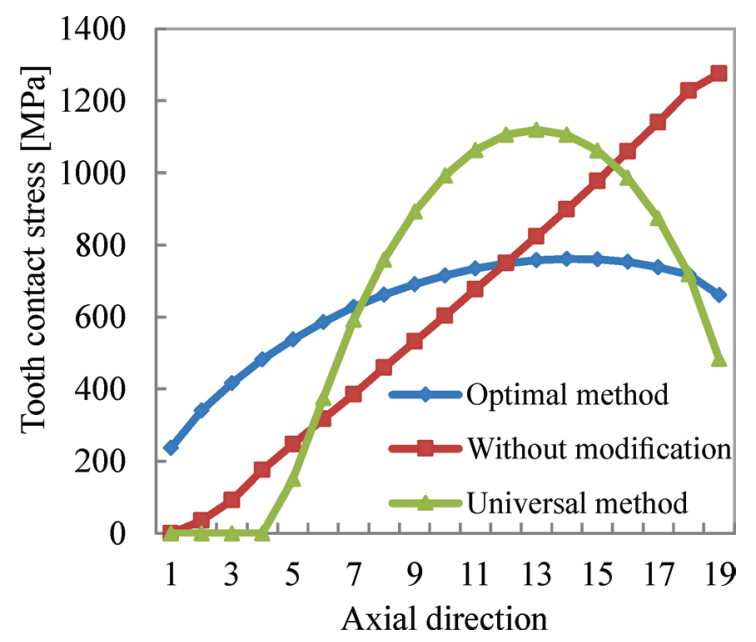

Fig. 9. Value of contact stress along the axial direction

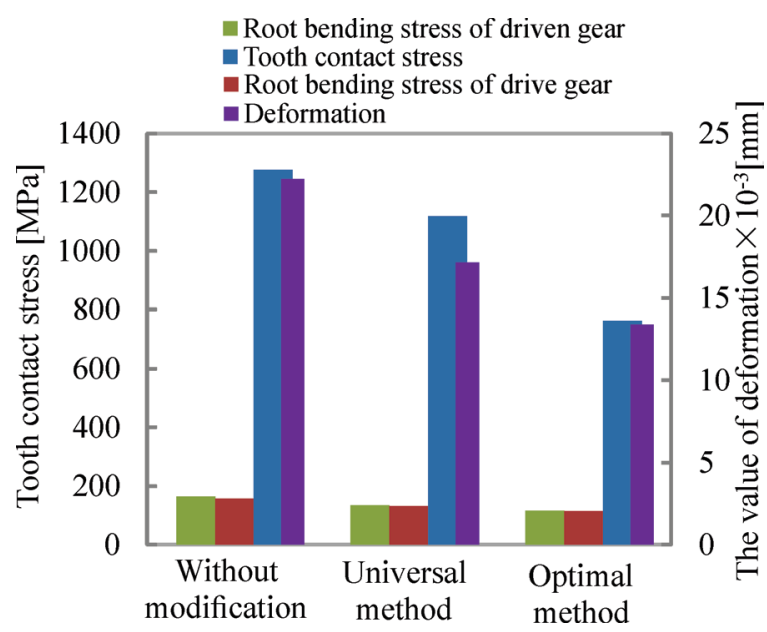

Fig. 10. Comparison of different methods

Moreover, the contact stress, the root bending stress of drive gear, the root bending stress of driven gear, and the tooth deformation are described as Fig. 10 when the gear pair is in the above three situations.

It is easily found that the stresses and the tooth deformation are dramatically decreased when the gear pair is modified with the method proposed in this study.

\section{EXPERIMENT}

For the purpose of verifying the validation of method proposed in this study, not only has the transient meshing analysis been performed, but it also has trail-produced the gear pair as shown in Table 3 and conducted running-in test. When the test finished, the actual conduct area of the gear pair without modification was shown as Fig. 11. It can be easily determined that there is severe uneven load distribution. In view of this situation, it is necessary to conduct axial modification for the gear pair.

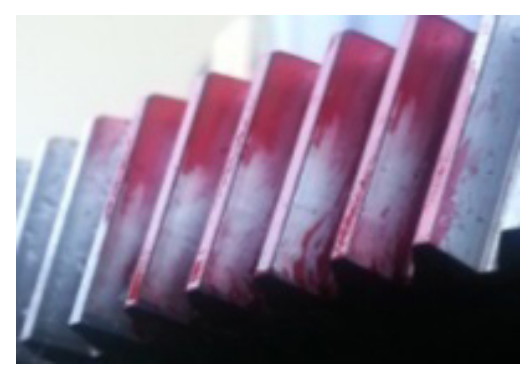

Fig. 11. Actual contact area of the gear without modification

Based on the method proposed in this study, the gear pair was modified with optimized modification parameters. A running-in test for the trail-produced modified gear pair and the actual contact area is shown as Fig. 12. The contact area locates approximately at the centre of the tooth width. And the phenomenon of uneven load distribution is obviously improved compared to the results in Fig. 11.

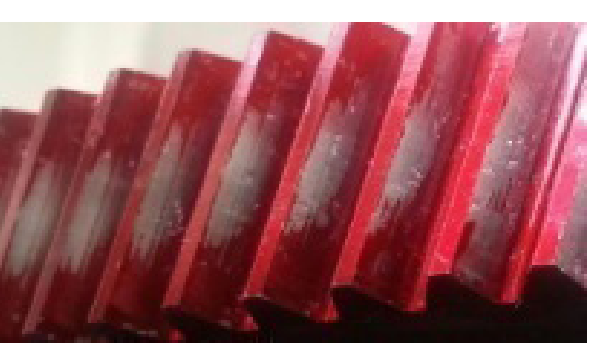

Fig. 12. Actual contact area of modified gear

\section{CONCLUSIONS}

An axial modification method is proposed based on the composite modification curve in this study, and the details of the process were introduced in 
this study. The comparison analysis verified the advantages of this method. In addition, the running-in tests were conducted after trail-producing gear pairs, and the results indicate the operability of the method. Moreover, the following conclusions can be drawn:

1. Conducting axial modification to the spur gear pairs with involute profile can improve the phenomenon of uneven load distribution and decrease the stresses of gears, thus the bearing capacity of a gear pair can be increased.

2. The modification effect is obtained by reading contact stress, root-bending stress of gears as well as tooth deformation and observing the situation of the contact area; modification parameters strongly influence the modification effect.

3. The modification method proposed in this study has stronger adaptability than the universal method.

In summary, it is meaningful to present a novel modification method and the assessment method to evaluate the modification effect to find suitable modification parameters for different gear pairs. However, the method proposed is only used in the transmission of spur gears at present. It will be applied to the bevel gears and the fatigue analysis will be considered in future study.

\section{ACKNOWLEDGEMENTS}

This work was supported by the National Natural Science Foundation of China (Grant No. 51674155), the Science and Technology Development Program of Shandong Province (Grant No. 2017GGX30127), the Special Funds for Cultivation of Taishan Scholars, the Shandong Provincial Natural Science Foundation of China (Grant No. ZR2016EEQ24), and the Innovation Foundation for Graduate Students of Shandong University of Science and Technology (Grant No. SDKDYC170330).

\section{REFERENCES}

[1] Korotkin, V.I., Gazzaev, D.A. (2011). Axial error of gears and the tooth stress state in involute gear systems. Russian Engineering Research, vol. 31, no. 9, p. 834-837, DOI:10.3103/S1068798X11090140.

[2] Barbieri, M., Zippo, A., Pellicano, F. (2014). Adaptive grid-size finite element modeling of helical gear pairs. Mechanism and Machine Theory, vol .82, p. 17-32, D0l:10.1016/j. mechmachtheory.2014.07.009.

[3] Barbieri, M., Bonori, G., Pellicano, F. (2012). Corrigendum to: Optimum profile modifications of spur gears by means of genetic algorithms. Journal of Sound and Vibration, vol. 331, no. 21, p. 4825-4829, D0l:10.1016/j.jsv.2012.05.028.
[4] Bonori, G., Barbieri, M., Pellicano, F. (2008). Optimum profile modifications of spur gears by means of genetic algorithms. Journal of Sound and Vibration, vol. 313, no. 3-5, p. 603-616, Dol:10.1016/j.jsv.2007.12.013.

[5] Baglioni, S., Cianetti, F., Landi, L. (2012). Influence of the addendum modification on spur gear efficiency. Mechanism and Machine Theory, vol. 49, p. 216-233, Dol:10.1016/j. mechmachtheory.2011.10.007.

[6] Liu, G., Parker, R.G. (2008). Dynamic modeling and analysis of tooth profile modification for multimesh gear vibration. Journal of Mechanical Design, vol. 130, no. 12, p. 121402-121414, DOI:10.1115/1.2976803.

[7] Chen, S.Y., Tang, J.Y., Chen, W.T., Hu, Z.H., Cao, M.P. (2014). Nonlinear dynamic characteristic of a face gear drive with effect of modification. Meccanica, vol. 49, no. 5, p. 10231037, DOl:10.1007/s11012-013-9814-8.

[8] Wu, Y.J., Wang, J.J., Han, Q.K. (2012). Static/dynamic contact FEA and experimental study for tooth profile modification of helical gears. Journal of Mechanical Science and Technology, vol. 26, no. 5, p. 1409-1417, D0l:10.1007/s12206-011-10281.

[9] Subramanian, R.B., Srinivasan, K. (2014). Vibration analysis of an influence of groove in the bottom land of a spur gear. Journal of Vibration and Control, vol. 20, no. 6, p. 847-858, DOI:10.1177/1077546312471363.

[10] Ahakeri Aski, F., Mirparizi, M., Sheykh Samani, F., Hajabasi, M.A. (2014). Vibration behavior optimization of planetary gear sets. Propulsion and Power Research, vol. 3, no. 4, p. 196206, DOI:10.1016/j.jppr.2014.11.002.

[11] İmrek, H. (2009). Width modification for gears with low contact ratio. Meccanica, vol. 44, no. 5, p. 613-621, Dol:10.1007/ s11012-009-9220-4.

[12] Düzcükoglu, H. (2009). PA 66 spur gear durability improvement with tooth width modification. Materials \& Design, vol. 30, no. 4, p. 1060-1067, D0I:10.1016/j.matdes.2008.06.037.

[13] Nejad, A.R., Xing, Y.H., Guo, Y., Keller, J., Gao, Z., Moan, T. (2015). Effects of floating sun gear in a wind turbine's planetary gearbox with geometrical imperfections. Wind Energy, vol. 18, no. 12, p. 2105-2120, Dol:10.1002/we.1808.

[14] Li, S.T. (2007). Effects of machining errors, assembly errors and tooth modifications on loading capacity, load-sharing ratio and transmission error of a pair of spur gears. Mechanism and Machine Theory, vol. 42, no. 6, p. 698-726, D0l:10.1016/j. mechmachtheory.2006.06.002.

[15] Li, S.T. (2015). Effects of misalignment error, tooth modifications and transmitted torque on tooth engagements of a pair of spur gears. Mechanism and Machine Theory, vol. 83, p. 125-136, D0I:10.1016/j.mechmachtheory.2014.09.011.

[16] Hotait, M., Kahraman, A. (2008). Experiments on root stresses of helical gears with lead crown and misalignments. Journal of Mechanical Design, vol. 130, no. 7, p. 074502-074506, DOI:10.1115/1.2931127.

[17] Hsu, R.H., Su, H.H. (2014). Tooth contact analysis for helical gear pairs generated by a modified hob with variable tooth thickness. Mechanism and Machine Theory, vol. 71, p. 40-51, Dol:10.1016/j.mechmachtheory.2013.09.001.

[18] Kawalec, A., Wiktor, J. (2008). Simulation of generation and tooth contact analysis of helical gears with crowned flanks. 
Proceedings of the Institution of Mechanical Engineers. Part B: Engineering Manufacture, vol. 222, no. 9, p. 1147-1160, D0I:10.1243/09544054JEM1104.

[19] Artoni, A., Guiggiani, M., Kahraman, A., Harianto, J. (2013). Robust optimization of cylindrical gear tooth surface modifications within ranges of torque and misalignments. Journal of Mechanical Design, vol. 135, no. 12, p. 121005 , DOI:10.1115/1.4025196.

[20] Tesfahunegn, Y.A., Rosa, F., Gorla, C. (2010). The effects of the shape of tooth profile modifications on the transmission error, bending, and contact stress of spur gears. Proceedings of the Institution of Mechanical Engineers, Part C: Journal of Mechanical Engineering Science, vol. 224, no. 8, p. 17491758, D0I:10.1243/09544062JMES1844.
[21] Song, L.M. (1987). Tooth Profile and Gear Strength. National Defense Press, Beijing.

[22] Piegl, L., Tiller, W. (2012). The NURBS Book. Springer Science $\&$ Business Media, Berlin.

[23] Zeng, Q.L., Wang, K., Wan, L.R., Zhang, X. (2017). Accurate modeling and transient meshing analysis of involute spur gear based on the principle of gear shaping. International Journal of Simulation Modelling, vol. 16, no. 2, p. 322-333, Dol: 10.2507/IJSIMM16(2)C07.

[24] Perec, A. (2016). Abrasive suspension water jet cutting optimization using orthogonal array design. Procedia Engineering, vol. 149, p. 366-373, D0l:10.1016/j. proeng.2016.06.680. 